\title{
COM \\ Differences in knowledge, uncertainty, and social context in four medical TV series from Taiwan, Japan, South Korea and the United States
}

\section{Yin-Yueh Lo and Chun-Ju Huang}

\begin{abstract}
Television series that mix real science and imagery science make up a fascinating genre in popular science. While previous research on entertainment media focuses on Western examples and seldom includes Asian TV series, this study explores how medicine is portrayed in four TV series located in a hospital setting which were broadcasted in Taiwan. Yet, they were produced in different cultures: Taiwan, Japan, South Korea and the United States. We found that the emphasis is more on the social contexts of medicine than on factual medical information. Yet, fictional TV series may be crucial for contextualizing science and science-based medicine.
\end{abstract}

Keywords

DOI

Introduction
Popularization of science and technology; Representations of science and technology; Science and media

https://doi.org/10.22323/2.20010201

Submitted: 29th January 2020

Accepted: 29th October 2020

Published: 11th January 2021

\section{$T V$ series as public communication of science}

Expecting benefits from increasing scientific knowledge throughout society, the Taiwan government has put much systematic effort toward improving public communication of science. In 2000, the government set up an annual National Science and Technology Week and launched a popular science education project. In 2007 a public funded project, Development of Taiwan Science Communication Industry, was launched that aims at developing diverse media products so as to enhance public communication of science [Huang, Li and Lo, 2020].

Entertainment media such as TV fiction series and movies are one of the most popular ways of drawing public attention to science. A survey showed that more than four in five U.S. adults watch science-related content in entertainment media covering criminal investigations, science fiction, or medicine [Funk, Gottfried and Mitchell, 2017]. That TV genre is popular in Taiwan as well [National 
Communications Commission, 2019]. This study thus focuses on medical TV fiction series that have been broadcasted in Taiwan.

Science-related entertainment media have attracted scholarly attention for both their popularity and relevance for the relationship of science and society.

Entertainment media visualize scientific objects, settings and processes for the public, while the storytelling narratives contextualize scientific knowledge and relate it to audiences' experiences. In their focus groups with media makers, pupils, students, and scientific consultants, Szu, Osborne and Patterson [2017] found that science-related content in the entertainment media was central to participants' discussion. The public generally shows a positive attitude toward science-related TV content and mostly agrees with the possible pedagogic functions of TV fiction [Davin, 2003], or at least does not feel that the fictional character impedes their understanding of the scientific knowledge [Funk, Gottfried and Mitchell, 2017]. Although science-related TV programs receive subsidies by Taiwan's Ministry of Science and Technology, few studies have analyzed the content of these programs while a number of studies have focused on how fictional TV series present social ideologies or gender issues [e.g. Tsai, 1994; Wang, 2000].

A dispute exists between science and the entertainment industry over scientific accuracy in TV series. Plots and images are often criticized as inaccurate or over-exaggerated [Moss-Wellington, 2020]. Focusing on the role of scientific consultants in science-related film productions, Kirby [2003a] and Kirby [2003b] argues that fictional TV series and movies provide a perceptually realistic framework that merges accurate and inaccurate science and rather serves as scientists" "promotional device for their research fields" [Kirby, 2003b, p. 231] than as a means of promoting science knowledge of the audience. Pansegrau [2007] also found that portrayals of science lack any scientific accuracy. Yet, focusing on science documentaries, Gouyon [2016] has a more positive view of how knowledge is presented and argues that film-makers in the documentary genre partner with scientists in the co-production of knowledge.

Scholars' assessments of the value of TV programs and films differ beyond the question of scientific accuracy. Based on an analysis of 65 TV shows and films, Fisher and Cottingham [2017] found that the fictional presentation of medical research presents biased stereotypes with respect to race and gender, for example. Looking at how science is framed in films or TV series, Gerbner [1987] found that although science and scientists had a slightly positive image in the media, it was less positive than that of other professionals such as medical practitioners or law enforcers. To explain the attenuated positive image of science, he argues that TV entertainment programs "reflect and exacerbate public ambivalence and anxiety about science" (p. 114). Görke and Ruhrmann [2003] point to the function of entertaining frameworks of science not for the dissemination of scientific knowledge but for the identification and perceptually realistic portrayal of social problems regarding science and its relation to the broader society.

Studies about science in fictional movies mostly focus on the Western culture. Kirby [2008] describes the transformation of scientific knowledge from the scientific community to the entertainment community as a 3-step process. Raw scientific information is first synthesized to a condensed scientific narrative, translated into a cinematically manageable narrative, and in the final stage transformed into 
cinematic representations (p. 173). According to this framework, culturally embedded elements such as interpersonal interactions within the scientific community should also be transmitted into cinematic settings - along with scientific factual knowledge. Yet, cross-cultural studies of interpersonal interaction show that interactions tend to vary across cultures. Thus, despite the universal validity of scientific knowledge, we may expect TV fictional narratives to differ between cultures. Although limited with respect to the number of series included in our analysis, this study aims to explore differences between four medicine-related TV series produced in Asian and Western culture.

Our discussion of possible cultural differences in the stories told in the series is guided by Hall's distinction between communication styles in high- and low-context cultures [Hall, 1976] and Hofstede's cultural dimension of uncertainty avoidance [Hofstede, 2011].

\section{High-context culture in East Asia vs. low-context culture in the West}

Anthropologist Edward T. Hall [1976] noticed that communication styles differ between high-context and low-context cultures according to a differing significance of the social context of communication. High-context cultures place emphasis on implicit communication and non-verbal cues. Background knowledge and context of a message are crucial for decoding its meaning. Communication is expected to take the social situation into account, both in interpreting messages of others and in deciding about what and how to communicate oneself. Conversely, communication in low-context cultures tends to be explicit with low significance of non-verbal cues and social context. Low-context cultures tend to view communication as a way to exchange information and opinions. This account of the communication styles is based on ideal typical reconstructions of high- and low-context cultures. Existing cultures are mixed types and the differences between them are a matter of degree, of course. The culture in Asian and Arabic countries is generally considered to be high-context while the culture in the United States and in West European countries is generally considered low-context [Arunthanes, Tansuhaj and Lemak, 1994].

Hall's theory points to further differences. According to him, members of a high-context culture are more sensitive to conflict in non-verbal cues than those of a low-context culture. Furthermore, the two cultures are thought to have different approaches in solving conflicts. Chua and Gudykunst [1987] demonstrated that members of high-context cultures are more likely to avoid confrontation in a conflict situation than members of a low-context culture. They also found that in a conflict situation, members of the latter are more solution orientated than those of the former.

The differences in communication style between high- and low-context cultures might lead to expectations regarding differences between TV medical series produced in Asia and the West. As people in a low-context culture are more inclined to consider communication as plain information exchange than those in a high-context culture, communication between characters in science-related TV series produced in the West may show more emphasis on knowledge exchange than communication between characters in Asian series. We would also expect to find different ways of dealing with conflicts in series produced in Asian versus those from Western countries. 
As Nisbett and Masuda [2003] have shown, members of high- versus low-context cultures do not only differ in communication styles but also in the way they perceive the world. In detecting changes, East Asians were more sensitive to changes in relationships and social environment than people from the West. And in the perception of emotions Asians are more likely to consider a scene's surrounding and background information, such as interpersonal relationships, than people from Western countries [Masuda et al., 2008]. Analyzing summaries of films written by American and Taiwanese college students, Nisbett and Masuda [2003] demonstrate that the latter wrote more about emotional states of various characters, whereas the former focused more on central characters.

The different emphasis on context in the perception of real-life and fictive reality in Asia and the West lets us presume that science-related TV series produced in Asia place more importance on the contextualization of science than series produced in the West.

\section{Uncertainty avoidance in East Asia vs. uncertainty acceptance in the West}

The Hofstede model of national culture is one of the most well-known for cultural comparison. Based on surveys in 85 countries, Geert Hofstede and his collaborators identified six dimensions of culture: uncertainty avoidance, power distance, individualism/collectivism, masculinity/femininity, long-/short-term normative orientation, and indulgence/restraint [Hofstede, Hofstede and Minkov, 2010]. Hofstede's model has been widely applied to show differences across cultures comparing collectivism in East Asian countries with individualism in Western countries, for example [e.g. Leonard, Van Scotter and Pakdil, 2009; Massey et al., 2001]. However, as scientific uncertainty is an important feature of the scientific process and also relevant in public communication of science [e.g. Peters and Dunwoody, 2016], we focus in our study on the uncertainty avoidance dimension. We expect that storylines in TV series may reflect the respective cultural tendency of accepting or avoiding uncertainty.

According to Hofstede [2011], uncertainty avoidance denotes a society's (in)tolerance for uncertainty and ambiguity and indicates to what extent members of a culture feel uncomfortable or comfortable in unstructured situations. A society that is high in uncertainty avoidance may try to minimize the possibility of uncertain situations through strict behavioral codes, rules, and disapproval of deviant opinions. Relevant in the context of public science communication is Hofstede's assumption that both relativism and empiricism are more likely to be highlighted in a society tolerating uncertainty than in a society that tries to avoid uncertainty. To minimize uncertainty in scientific knowledge, an uncertainty avoidance society is more likely to seek out ultimate truths and grand theories than an uncertainty acceptance society. A society's tendency toward uncertainty acceptance/avoidance may result in different cross-cultural expectations on scientist experts. For example, it is acceptable in an uncertainty acceptance culture that experts admit the limitation of their knowledge without being discredited, whereas experts in a strong avoidance culture are expected to have all the answers [Hofstede, 2011, p. 10].

Uncertainty avoidance tends to be higher in East Asia and lower in English-speaking countries. On Hofstede's scale, Japan, South Korea and Taiwan 
are more uncertainty avoidant than the United States [Hofstede, Hofstede and Minkov, 2010]. For experts in an uncertainty accepting culture it is possible to admit limitations of their knowledge and this might affect the storylines in TV series.

\section{Objectives}

The goal of our analysis is to explore how TV series broadcasted in Taiwan portray medicine and medical knowledge and, in particular, how the medical characters in the stories of these series respond to uncertainty. Furthermore, we also aim to explore how the focus related to medicine and medical knowledge differs across TV series and whether these differences relate to theoretical descriptions of cultural differences.

Previous studies on medicine in popular culture focused mostly on specific health problems, such as cardiopulmonary resuscitation [cf. Harris and Willoughby, 2009] or Schizophrenia [cf. Owen, 2012]. In our study, we are particularly interested in how the series make references to scientific progress in their depiction of medical practices related to diagnosis and treatment of diverse health problems. Regarding scientific uncertainty, this study focuses on how TV series figures characterize, assess, and convey uncertainty. Fischhoff and Davis [2014, p. 13664] mention three kinds of decisions in which uncertainty may exist: "decisions about action thresholds" (When is it time to act), "decisions with fixed options" (Which one is the better or the best option?), and "decisions about potential options" (What are other possibilities?). Following Kirby [2008] who argues that the cultural context may influence how interpersonal interactions, e.g. among scientific peers, are cinematized, we aim to analyze how the medical staff communicates about uncertainty.

For this exploratory study we selected four TV medical series from Japan, South Korea, Taiwan, and the United States. By including a U.S. TV series along with three Asian series we wanted to increase the cultural variation along the dimensions of context relevance (high- versus low-context) and uncertainty avoidance. Based on our discussion of differences between low- and high-context cultures in the introduction, we present two hypotheses:

Hypothesis 1: Western fictional medical TV series are more likely to include factual medical information such as medical explanations and references to medical progress than Asian TV series.

Hypothesis 2: Asian fictional medical TV series are more likely to focus on the organizational and social context than Western TV series.

The difference in uncertainty acceptance between Western and Asian cultures imply different approaches toward decision making - for example, in determining which clinical treatment is the best for the patient.

Hypothesis 3: Medical experts (doctors) in Western series are more likely to express uncertainty than their counterparts in Asian series. 
However, while the three hypotheses about possible cultural differences have guided our research, we also aim at an exploratory description of the medical TV series in general - focusing on how they present medical progress and factual information, deal with uncertainty, and cover the social context of medical practice.

For our analysis we selected four fictional medical TV series from Japan, South Korea, Taiwan and the United States that were adapted with Mandarin subtitles and broadcasted in Taiwan 2012-2015:

Team Medical Dragon (Japan 2014, $4^{\text {th }}$ season) is about a medical surgery team led by a genius surgeon who is devoted to fighting corruption in Japan's medical system and to saving patients with rare diseases.

Emergency Couple (South Korea 2014, $1^{\text {st }}$ season) focuses on the relationship between two interns in an emergency room and on the other characters around them.

Wake Up (Taiwan 2015, $1^{\text {st }}$ season) shows how Dr. Hsiao Zheng Xun, an anesthesiologist, is fighting for justice and struggling to reestablish his reputation after he was made the scapegoat for a patient's death from a rare complication during an anesthesia that was actually performed by his superior.

House, M.D. (U.S.A. 2012, $8^{\text {th }}$ season) focuses on Dr. Gregory House, a physician with an eccentric character and unconventional medical approaches, and on the interactions with his medical team and the hospital's management.

The content analysis consists of a quantitative and a qualitative part. For the quantitative analysis, the first six episodes of each series were analyzed using "scene" as the unit of analysis. The coding book consists of six categories that code presence or absence of the respective content in a scene as dummy variables (Table 1). The first three categories - unexplained jargon, progress, medical explanation - refer to the inclusion of factual medical information in a scene. If a scene contains at least three clinical terms without further explanations, then the scene is coded as containing "unexplained jargon" [V1]. Such scenes appear mostly in clinical operation settings, when the chief physician gives orders to assistants. The category "progress" [V2] records references to recent medical advances that in the context of journalism might be considered as newsworthy. "Medical explanation" [V3] is coded if information about causes and symptoms of an illness is included in the scene. The fourth category records expressions of "uncertainty" in a scene [V4]. The last two categories - "justice issue" and "organizational issue" - operationalize two kinds of references to the social context. "Justice issue" [V5] is coded if violations of normative social expectations are mentioned in a scene. In particular this concerned the question of whether all patients deserve or receive medical treatment of the same quality. Finally, "organizational issue" [V6] is applied if references to the hospital as organization are made.

The number of analyzed scenes ranges from 221 (Wake Up, Taiwan) to 294 (Team Medical Dragon, Japan); overall 982 scenes were coded on the basis of transcriptions 
Table 1. Category system for the content analysis. The binary categories were used to code existence or absence of the respective content feature in each scene.

\begin{tabular}{|l|l|l|l|}
\hline \multicolumn{4}{|c|}{ Definitions of variables and examples } \\
\hline Variable & Category & Definition & Example \\
\hline V1 & $\begin{array}{l}\text { Unexplained } \\
\text { jargon }\end{array}$ & $\begin{array}{l}\text { At least three medical } \\
\text { terms without further } \\
\text { explanations are } \\
\text { mentioned }\end{array}$ & $\begin{array}{l}\text { "Transcathether aortic } \\
\text { valve implantation, } \\
\text { diruretic, suture 3-0" }\end{array}$ \\
\hline V2 & Progress & $\begin{array}{l}\text { A doctor refers to recent } \\
\text { advance or scientific } \\
\text { research }\end{array}$ & $\begin{array}{l}\text { "According to the latest } \\
\text { scientific journal..." }\end{array}$ \\
\hline V3 & $\begin{array}{l}\text { Medical } \\
\text { explanation }\end{array}$ & $\begin{array}{l}\text { Cause, symptom, or } \\
\text { treatment of an illness is } \\
\text { explained }\end{array}$ & $\begin{array}{l}\text { "Arrhythmia is an } \\
\text { irregular heartbeat that } \\
\text { might require treatment." }\end{array}$ \\
\hline V4 & Uncertainty & $\begin{array}{l}\text { Uncertainty about } \\
\text { diagnosis, treatment, or } \\
\text { prognosis of a medical } \\
\text { condition is expressed }\end{array}$ & $\begin{array}{l}\text { "Asthma leads to } \\
\text { symptoms of wheeze, } \\
\text { dyspnea and cough. } \\
\text { However, this patient has } \\
\text { only cough." }\end{array}$ \\
\hline V5 & Justice issue & $\begin{array}{l}\text { A decision causes injustice } \\
\text { (even implicitly) }\end{array}$ & $\begin{array}{l}\text { "Patients with a lot of } \\
\text { fortune in our hospital } \\
\text { deserve to be treated as } \\
\text { VIP." }\end{array}$ \\
\hline V6 & $\begin{array}{l}\text { Organizational } \\
\text { issue }\end{array}$ & $\begin{array}{l}\text { Organizational matters of } \\
\text { the hospital are mentioned } \\
\text { "To improve our hospital's } \\
\text { revenue, a reform will be } \\
\text { launched with respect to } \\
\text { education, clinical } \\
\text { routines, and research." }\end{array}$ \\
\hline
\end{tabular}

of the episodes. Three college junior students transcribed the episodes and served as coders. All three coders had taken a two-credit course "Science in film", in which they learned to be attentive to science-related issues in films. Before starting the transcription and coding, the coders were trained in a two-day training workshop on how to define begin and end of a scene and how to apply the categories. Test coding of a 45-minutes episode during the training and discussion of the results of the coding until agreement was reached ensured a common understanding of the meaning and application of the categories.

After training, the 982 scenes were coded. Since the content aspects we are interested in are partly implicit and require interpretation, the three coders independently coded all scenes and we determined the final code by majority rule, selecting the code on which at least 2 of the 3 coders agreed. Intercoder reliability analysis based on Cohen's Kappa - calculated with R 2.6.3 - revealed "substantial" intercoder reliability for "unexplained jargon" [V1] (average kappa values of the three pairs of coders of .73) and "fair" reliability for the categories "progress" (.21), "medical explanation" (.26), "uncertainty" (.27), "justice issue" (.27), and "organizational issue" (.39). The reliability of two further categories were only "slight" $(<.20)$, and we therefore excluded these categories from the presentation of results. The assessment of the reliability figures as "substantial", "fair" and "slight" follows the interpretation of the kappa statistics by Landis and 
Koch [1977]. All reported kappa values are highly significant $(p<.0001)$, and because of the majority rule approach the coding results are more reliable than the kappa figures suggest.

As scientific uncertainty is manifold [cf. Peters and Dunwoody, 2016], we also conducted an exploratory qualitative analysis looking in more detail into how uncertainty is framed and tackled in the storylines of individual episodes. The goal of this analysis is to show by means of examples how uncertainty and ambivalence in medical treatment are communicated within the fictional medical teams, making use of the categorization by Fischhoff and Davis [2014] mentioned in the previous section.

Findings of our analysis surprisingly show that the communication of medical knowledge plays only a marginal role in these medical TV series. Medical explanations [V3] hardly occur at all; only one of the almost 1,000 scenes included an explanation. References to medical progress [V2] are rare too. Overall, only about $2.5 \%$ of the scenes include such as reference. The Japanese series Medical Dragon Team has the most of such scenes (nearly 6.0\%), while the Korean series Emergency Couple includes not a single one. The differences in the frequency of references to medical progress between the series is statistically significant $\left(\chi^{2}=21.2, p<0.001\right)$. However, the results do not conform with our expectations about cultural influences stated in hypothesis 1. Not the U.S. series House, M.D. but Medical Team Dragon from Japan contains most knowledge-related scenes in terms of references to medical progress.

Quite interesting is the high prevalence of unexplained medical jargon [V1] in the series. Overall, more than one in ten scenes contain three or more terms of unexplained medical jargon. Again, the difference between the series is statistically significant $\left(\chi^{2}=26.4 ; p<0.001\right)$. The U.S. series contains more unexplained medical jargon than the three Asian series; the difference between U.S. and Japanese series being lowest. This is in line with the assumption that communication in Western countries is more focused on factual information (hypothesis 1); yet, in fictional products the focus on facts may be reflected in symbolic rather than substantial references.

As Bullock et al. [2019] show, the use of jargon hinders effective science communication with the public. Medical jargon thus is not included as means of knowledge transfer but rather seems to have an important dramaturgical function in constructing medical authenticity. Contrary to the expectation of the Taiwanese government mentioned in the introduction, medical TV series follow a strict entertainment logic rather than pursue educational goals. Thus, while jargon may be a barrier in the context of science communication with the public, it may also be important for creating authenticity in a medical TV series.

\section{More contextualizing of medicine in Asian TV series}

While medical knowledge is hardly communicated to the audience, medical TV series seem more relevant in contextualizing medicine and connecting it to 
everyday experience. In contrast to the limited number of scenes dealing with medical advances and explanations, the TV series more frequently present moral conflicts and issues related to the social environment of professional practice. Nearly $7 \%$ of all scenes reflect on issues of justice [V5] and around $8 \%$ deal with aspects such as the rigid bureaucracy and corruption in medical organizations [V6]. Combining the two forms of social contextualization and taking into account that they partly overlap (i.e. co-occur in a number of scenes), about $13 \%$ of all scenes present context aspects.

Medical TV series thus present hospitals not only as institutions promoting health, but also as organizations with stakeholder interests that may sometimes clash with patients' interests and may even compromise patients' access to proper medical services. All four series have more scenes related to context aspects than to medical explanation [V3] or progress [V2]. The emphasis on contextualization over knowledge in medical TV series that we found in our study corresponds to the claim by Görke and Ruhrmann [2003] that such TV series are important for audiences' understanding of the social context of scientific practice - despite the weakness of entertaining formats in mediating scientific knowledge.

Combining the two variables indicating contextualization [V5 and V6], we find that story plots related to context differ significantly $\left(\chi^{2}=43.5, p<0.001\right)$ across the four series. Context references are far more prevalent in the Taiwanese $(23 \%)$ and Japanese series (17\%) than in the U.S. series (6\%). This seems to confirm hypothesis 2, claiming more attention for the context in Asian than Western series. Yet, the South Korean series (6\%) does not fit into the expected pattern. It might be that the specific story plot of the South Korean series that focused on the relationship of a couple, implements a kind of psychological contextualization that we did not cover with our categories. Thus, our hypothesis 2 is not convincingly supported by our study.

\section{More uncertainty and ambivalence in the U.S. series}

About $8 \%$ of the 982 scenes deal with uncertainty or ambivalence in medical treatments [V4], ranging from 2\% in Wake Up (Taiwan), 5\% in Emergency Couple (South Korea), 9\% in Team Dragon (Japan), to 13\% in House, M.D. (United States). Comparing across cultures, the U.S. series presents more medical uncertainty than the three Asian series $\left(\chi^{2}=21.89, p<0.01\right)$. This result confirms our hypothesis 3 that Western TV series more frequently present uncertainty than Asian TV series and is consistent with Hofstede's finding of cultural differences in uncertainty avoidance.

The next section presents the results of the qualitative analysis of medical uncertainty in the TV series. Based on the result of the quantitative analysis, scenes dealing with uncertainty were selected for the qualitative analysis with the aim of characterizing the uncertainty discourses in these scenes in more detail. As heuristics for the analysis the three classes of decisions in dealing with uncertainty (Is it time to act? Which option is best? What is possible?) of Fischhoff and Davis [2014], and Hofstede's [2011] insights into the consequences of uncertainty avoidance for a society's expectations towards experts were used. 


\section{Types of uncertainty: "What is possible" vs. "Which option is best"}

The narratives of House, M.D. focus on diagnosing. A typical storyline in an episode begins with a patient's unknown illness. The medial team is unable to make sense of the symptoms a patient shows. The team then starts a trial-and-error process that sometimes seems erratic until the correct diagnosis is finally found. For example, two scenes in the $5^{\text {th }}$ episode of House, M.D. illustrate the reasoning within the medical team.

Park: There wasn't any abnormal electrical activity in his E.K.G. when his seizure occurred. It wasn't caused by a V-fib.

Adams: We still can't rule it out. His E.K.G from the E.R. documented [...].

Chase: Myocardities. Viral infection weakening the wall muscles.

House: We need to biopsy his heart to confirm. Myocarditis wouldn't cause a seizure.

Taub: Could be genetic — Brugada Syndrome.

House: $[\ldots]$ We would have seen evidence of Brugada in the E.K.G. [...].

Park: A pheochromocytoma. Excess adrenaline can cause heart problems and seizures [...].

House: [...] Nope. You're wrong. Photic epilepsy [...] give him an E.E.G. to confirm.

[...]

Chase: The E.E.G. didn't show any abnormal brain activity.

Adams: He doesn't have photic epilepsy.

House: I know, because he has a pheochromocytoma.

Park: You said I was wrong.

House: You were wrong not to rule out epilepsy first. That only takes a couple of hours. Finding a tumor that's flushing adrenaline through his system is gonna take all night. [...]

This dialogue illustrates that the diagnosis of a disease is based on a succession of tests. The medical team does not choose from a predefined set of options but uses an open research approach considering more and more hypothesis until one diagnosis fits the symptoms.

Unlike House, M.D., episodes of the three Asian TV series often begin with a diagnosis considered certain, followed by scenes where doctors dispute the correctness of it.

For example, in one scene a patient suddenly experiences an emergency situation ( $6^{\text {th }}$ episode in the $4^{\text {th }}$ season of Medical Dragon). Two doctors (Asada and Noguchi) argue about the correct prognosis (bronchial asthma or cardiac asthma) and the appropriate treatment ( $\beta 2$-stimulant or $\beta$-blocker).

Kato: She complained of having difficulty in breathing, then collapsed in the lobby. I've listened to the wheezing of both her lungs. It's an asthma attack. $[\ldots]$ 
Asada: Please prepare $\beta$-blocker. [...]

Noguchi: Did you say $\beta$-blocker? What a stupid thing. It should be $\beta 2$-stimulant if it's bronchial asthma, right? If you use a $\beta$-blocker, her breathing will stop, and worse it will lead to death. Your medical license will be stripped due to a medical malpractice.

Asada: She's not having a bronchial asthma. It's a cardiac asthma.

Noguchi: What are you saying? The specialist in respiratory medicine in L\&P has diagnosed her after taking a CT. It has been determined as bronchial asthma; $\beta 2$-stimulant it is.

[Ignoring Dr. Noguchi's different opinions and protests, Dr. Asada shoots $\beta$-blocker into the patient.]

Kato: The attack has subsided. [...]

Asada: When Hirayama-san was filled with emotions, [... ] I learned that there's a engorgement in the jugular vein. Furthermore, there's also an edema of lower limbs. These are obviously the symptoms of cardiac asthma. Moreover, according to Dr. Sakurai's medical record, there is a systolic murmur from the auscultation and also a split of the second heart sound. That's why I used a $\beta$-blocker.

This example shows an argument between two doctors about the correctness of the diagnosis. Admittance of uncertainty in the Asian storyline is not apparent. Both doctors are confident about their respective diagnoses and hold firm but discrepant beliefs about the proper treatment. The audience is provided with two options. The dispute is resolved not through argumentation and tests but by one actor (Dr. Asada) dominating the other by assuming control and acting according to his opinion without further clinical tests. In the storyline the results (the attack subsided) justify Dr. Asada's treatment; the rational for it is only given afterwards. Scenes of this storyline involve limited uncertainty (bronchial asthma or cardiac asthma), as well limited treatment options ( $\beta$-blocker or $\beta 2$-stimulant). In contrast to this setting, uncertainty about diagnosis and proper treatment in House, M.D. is not limited to a set of options at the beginning of the examination.

In the episode from Medical Dragon, uncertainty about whose diagnosis and treatment proposal is correct is limited to the external observer, i.e. the audience. The characters of the plot are shown as acting on the basis of subjective certainty, displaying an attitude and behavior corresponding to the assumption of Hofstede [2011] that the public in an uncertainty avoiding culture expects experts to exhibit omniscience. To claim professional authority, experts must not reveal their uncertainty.

\section{Decision-making in resolving uncertainty: scientific evidence vs. status hierarchy}

How the medical teams in the TV series approach uncertainty reveals cultural differences and corresponds to the communication style in high- and low-context cultures. Even as leader of the medical team, House does not claim to have definite knowledge about the illness of the patient; his presumption is uttered as hypothesis that needs to be tested. Uncertainty is dealt with by a group discussion in which each team member has the opportunity to express opinions and even to disagree with the leader; decisions about the validity of claims are based on results of clinical tests, not on status hierarchy. A member of the team, whose initial 
judgement turns out to be correct, could challenge the leader's previous critical response to his claim (Park: "You said I was wrong"). The leader had to justify and qualify his criticism (House: "You were wrong not to rule out epilepsy first...").

Resolution of uncertainty in a high-context culture relies on status hierarchy. This mechanism avoids interpersonal confrontation, as Chua and Gudykunst [1987] argue. In the example above, the leader (Dr. Aseda) acts according to his assessment without considering the criticism by his staff seriously, and without even explaining the reasoning behind his assessment. By not responding to the critical objections of his staff members, he avoids an open dispute. The uncertainty about how to act, obvious to the audience of this episode, is resolved by a decision of the leader. The successful outcome of the decision, and the ex post explanation by the leader that exposes his superior wisdom, legitimize this culture-conforming style of uncertainty resolution to the audience.

Wake Up (Taiwan) provides another example of how uncertainty is resolved by hierarchy. There is some obvious disagreement about whether to accept an emergency patient who is already on the way the hospital. However, the director (Dr. Chen) of that hospital asks his subordinates (Dr. Lin and Dr. Yeh) to turn down the request.

Lin: Sir, there's going to be a trauma surgery. The patient has a torn liver and has gone into shock. The ambulance will be here in ten minutes.

Chen: Request the ambulance to change its route. We don't have adequate infrastructure to handle this patient.

Lin: If we transfer him now, he can't get to another hospital in time.

Chen: Tell the ambulance to turn around. Listen to me if you still consider me as your teacher. Tell the ambulance to reroute.

$[\ldots]$

Yeh: We need to trust Dr. Chen's judgment. We can't save him with the equipment we have. [...]

Lin: How do you know without even trying?

Yeh: How confident are you? Fifty percent? Not even 30 percent? We'll probably even get in trouble.

This dialogue may be interpreted as showing a clash between the Western and the Asian style of uncertainty resolution. There is a discourse with fact-based arguments between the leader and the subordinates exposing a conflict over decision uncertainty, the staff members pointing to the urgency of the case and the leader to the lack of adequate medical infrastructure. But there is also the attempt to re-establish hierarchy as a means of resolving this conflict by mobilizing moral authority ("... if you still consider me as your teacher"). Thus, a potential confrontation between superior and subordinates is tamed; the leader offers his subordinates a face-saving way to knuckle down. In the end, the Asian-style conflict resolution is implemented, and the second part of the dialog shows that the two subordinates comply ("We need to trust Dr. Chen's judgment") — one more readily than the other.

This part of qualitative analysis shows the different patterns of how uncertainty is addressed in the U.S. series and the Asian series. Conforming with Hofstede's 
assumption that an uncertainty acceptance society is more tolerant of deviant ideas than an uncertainty avoidance society, the U.S. series presents another type of uncertainty (what is possible?) than the Asian series do (which is the best option?). Second, the approaches to reducing uncertainty differ: the U.S. series presents an evidence-centered approach based on trial-and-error strategies and open dispute, while the Asian series present interpersonal confrontations over different opinions as something to avoid and resolution of uncertainty by assumed superior knowledge and responsibility of leaders.

Discussion and conclusions
Contrary to the expectation of the Taiwanese government who sponsors the production of science- and medicine-related series with the expectation that these series contribute to the scientific or medical literacy of the audience, none of the series presents explicit knowledge of that type - at least not in the verbal exchanges among the characters of the series. The high prevalence of unexplained jargon shows that references to special medical knowledge frequently occur in the series, but only in a symbolic form. The intention of producers to include such symbolic references to medical knowledge may be to increase the authenticity of the fictional stories. Also, the government's expectation that such series will demonstrate the benefits of scientific research to the Taiwanese audience of these series is not reflected in a noteworthy number of explicit references to scientific research and progress.

In several respects, viewers may learn something, though. First, while we did not systematically analyze the visual content of the series, it is quite obvious that viewers of these series become familiar with the hospital settings and with the procedures of high-tech medicine - even if it the depiction of both is not realistic in every detail. The high proportion of scenes with unexplained jargon suggests that viewers might also derive the image from these series that science-based medicine is quite distinct from everyday world and knowledge. This emphasis on the difference between scientific special knowledge and everyday knowledge may cause cognitive alienation of the audience from this practice. But it may also contribute to the appreciation of modern science-based medicine - as the stories usually present medical knowledge and practice as successful and beneficial for the patients in the hospital.

Secondly, while the series do not educate the audience about medical research and practice in terms of diagnosis, therapy and causes of diseases, it may learn something about the social context in which medicine is practiced. Matching findings of previous studies [Czarny, Faden and Sugarman, 2010; Goodman, 2007], our analysis shows that the series focus on the social context of medical practice. This focus was particularly strong for the Taiwanese series Wake up. The scriptwriter John Collee [1999] argues that the combination of cognitive inaccessibility of modern medicine and its accessibility as social practice makes medical TV series attractive to the audience:

"[T]he fact that we don't understand the medical process makes us more appreciative of its complexity. The chaos and the jargon engage us intellectually in trying to work out what's happening. The moral ambiguity adds richness and depth while enabling us to put our own interpretations on events" (p. 955). 
Narratives focusing on the social context of medicine show that medicine is not only regulated by professional criteria but also influenced by interfering interests and expectations of the hospital as social organization, and that social norms and practices sometimes conflict with the medical ethos and cause issues of justice in the distribution of medical resources. From an educational point of view, this focus might be important [e.g. Jarrentrup et al., 2018]. As Görke and Ruhrmann [2003] argue, the broader function of fictional accounts of science may be to point to the issues deriving from the its social context. An analogous argument can be made for fictional narratives of science-based medicine which may help the audience understand medicine as a social system and stimulate its interest in the governance of medicine.

Thirdly, the form of communication among the medical teams tells the audience something about the way medical professionals argue and come to conclusions about diagnoses and therapies in the face of uncertainty. The examples presented in the qualitative analysis show that uncertainty is presented differently as uncertainty about the best choice from a set of options, or as open inquiry in which the possible outcomes are unknown. The examples also show that the decision-making style differs between one that is based on a trial-and-error approach implemented as discourse among the team members in which arguments and evidence count (House, M.D., U.S.) and one that relies on the superior wisdom or authority of the doctor with the highest social status (Medical Dragon, Japan, and Wake Up, Taiwan).

In the introduction we had stated three hypotheses about differences between the series based on theories claiming differences between Western and East Asian culture. We expected more factual information in the Western than Asian series (hypothesis 1), a stronger focus of Asian than Western series on the social context (hypothesis 2), and more expressions of uncertainty in Western than Asian series (hypothesis 3). We do actually find several significant differences between the four series (Table 2) but these differences do at most partly conform to our hypotheses.

As discussed above, neither series included factional information in the form of medical explanations; symbolic references to knowledge in the form of unexplained jargon are indeed more frequent in the series from the U.S. than in the Asian series which would conform to hypothesis 1 ; yet, there is hardly a difference between the U.S. and Japan. Social contextualization of science operationalized as references to organizational issues is highest in Taiwan and lowest in the U.S. This conforms to hypothesis 2; yet, the frequency of reference to organizational issues is also very low in South Korea. This might have to do with the plot of the South Korean series the core of which is the relationship of a couple. There is no significant difference regarding the frequency of justice issues, another aspect of social contextualization.

Comparing the frequency of expressions of uncertainty in the four series, hypothesis 3 based on the theoretical expectation of higher uncertainty avoidance in Asian countries is confirmed - but only if we compare the U.S. series with the average of the three Asian series; the Japanese series is not very different from the U.S. series. However, the qualitative analysis showed Asian series to present a different form of dealing with uncertainty that conforms to the theories of cultural differences. 
Table 2. Comparison of the four TV series regarding the portrayal of medicine. Percentages show the proportion of scenes with the respective content feature.

\begin{tabular}{|l|c|c|c|c|c|c|c|}
\hline & $\begin{array}{c}\text { Team } \\
\text { Medical } \\
\text { Dragon } \\
\text { (Japan) } \\
(n=294)\end{array}$ & $\begin{array}{c}\text { Emergency } \\
\text { Couple } \\
\text { (South } \\
\text { Korea) } \\
(n=225)\end{array}$ & $\begin{array}{c}\text { Wake Up } \\
\text { (Taiwan) }\end{array}$ & $\begin{array}{c}\text { House, } \\
\text { M.D. } \\
\text { (U.S.A.) }\end{array}$ & Total & $\chi^{2}$ & $p$ \\
\hline $\begin{array}{l}\text { [V1] } \\
\text { Unexplained } \\
\text { jargon }\end{array}$ & $16.3 \%$ & $9.8 \%$ & $7.7 \%$ & $22.7 \%$ & $11.4 \%$ & 26.4 & $p<0.001$ \\
\hline $\begin{array}{l}\text { [V2] } \\
\text { Progress }\end{array}$ & $5.8 \%$ & $0.0 \%$ & $1.8 \%$ & $1.2 \%$ & $2.4 \%$ & 21.2 & $p<0.001$ \\
\hline $\begin{array}{l}\text { [V3] } \\
\text { Medical } \\
\text { explanation }\end{array}$ & $0.0 \%$ & $0.0 \%$ & $0.0 \%$ & $0.4 \%$ & $0.1 \%$ & $-{ }^{\mathrm{a}} \%$ & \\
\hline $\begin{array}{l}\text { [V4] } \\
\text { Uncertainty }\end{array}$ & $9.2 \%$ & $4.9 \%$ & $2.3 \%$ & $12.8 \%$ & $7.5 \%$ & 21.9 & $p<0.001$ \\
\hline $\begin{array}{l}\text { [V5] } \\
\text { Justice issue }\end{array}$ & $5.4 \%$ & $4.9 \%$ & $10.4 \%$ & $5.8 \%$ & $6.5 \%$ & 7.2 & n.s. \\
\hline $\begin{array}{l}\text { [V6] } \\
\text { Organizational } \\
\text { issue }\end{array}$ & $11.9 \%$ & $1.3 \%$ & $18.6 \%$ & $0.4 \%$ & $8.2 \%$ & 70.8 & $p<0.001$ \\
\hline
\end{tabular}

a Due to cells with low frequencies, chi-square cannot be calculated.

While the theories of cultural differences presented in the introduction point to interesting content features regarding presentation of medical practice and reasoning about diagnoses and therapies that significantly differed between the four fictional medical TV series, these differences can only partly be explained with the cross-cultural framework. This may simply be due to variations of the narratives of productions even within a single culture, or with the limited number of content analytical indicators we used that may have missed other ways in which the cultural characteristics described by Hall [1976], Hofstede, Hofstede and Minkov [2010], and Masuda et al. [2008] are expressed. However, the inconclusive results may also have to do with the internationalization of the production and reception of series and films, leading to a convergence of production criteria and audience expectations across cultures.

\section{Limitations}

We have to acknowledge methodological limitations of our exploratory research. We only analyzed four medical TV series and the quantitative content analysis included only six content indicators operationalizing the dimensions of uncertainty avoidance, interpersonal communication styles, and focus of attention on relationships and context rather than on factual knowledge and the core plot. Even if the association between the characteristics of narratives in fictional series with the cultural production context turned out to be weaker than anticipated, the theories of cross-cultural differences helped us to focus on interesting content features that are worth being followed in a more comprehensive study of TV series dealing with science and medicine. Such as study should include a more representative sample of fictional content from the cultures to be compared and develop a richer set of content indicators that capture more nuances of possible cross-cultural differences. 
Arunthanes, W., Tansuhaj, P. and Lemak, D. J. (1994). ‘Cross-cultural business gift giving: a new conceptualization and theoretical framework'. International Marketing Review 11 (4), pp. 44-55. https://doi.org/10.1108/02651339410069245.

Bullock, O. M., Amill, D. C., Shulman, H. C. and Dixon, G. N. (2019). ‘Jargon as a barrier to effective science communication: evidence from metacognition'. Public Understanding of Science 28 (7), pp. 845-853. https://doi.org/10.1177/0963662519865687.

Chua, E. G. and Gudykunst, W. B. (1987). 'Conflict resolution styles in low- and high-context cultures'. Communication Research Reports 4 (1), pp. 32-37.

Collee, J. (1999). 'Medical fiction'. BMJ 318 (7189), pp. 955-956. https://doi.org/10.1136/bmj.318.7189.955.

Czarny, M. J., Faden, R. F. and Sugarman, J. (2010). ‘Bioethics and professionalism in popular television medical dramas'. Journal of Medical Ethics 36 (4), pp. 203-206. https://doi.org/10.1136/jme.2009.033621.

Davin, S. (2003). 'Healthy viewing: the reception of medical narratives'. Sociology of Health and Illness 25 (6), pp. 662-679. https://doi.org/10.1111/1467-9566.00364.

Fischhoff, B. and Davis, A. L. (2014). 'Communicating scientific uncertainty'. PNAS 111 (Supplement 4), pp. 13664-13671. https://doi.org/10.1073/pnas.1317504111.

Fisher, J. A. and Cottingham, M. D. (2017). ‘This isn't going to end well: fictional representations of medical research in television and film'. Public Understanding of Science 26 (5), pp. 564-578. https: / /doi . org/10.1177/0963662516641339.

Funk, C., Gottfried, J. and Mitchell, A. (20th September 2017). 'Science news and information today'. Pew Research Center. URL: https://www. journalism. org/20 17/09/20/science-news-and-information-today/.

Gerbner, G. (1987). 'Science on television: how it affects public conceptions'. Issues in Science and Technology 3 (3), pp. 109-115. URL: http://www. jstor.org/stable/43309074.

Goodman, K. (2007). 'Imagining doctors: medical students and the TV medical drama'. AMA Journal of Ethics 9 (3), pp. 182-187. https://doi.org/10.1001/virtualmentor.2007.9.3.medu1-0703.

Görke, A. and Ruhrmann, G. (2003). 'Public communication between facts and fictions: on the construction of genetic risk'. Public Understanding of Science 12 (3), pp. 229-241. https://doi.org/10.1177/0963662503123002.

Gouyon, J.-B. (2016). 'Science and film-making'. Public Understanding of Science 25 (1), pp. 17-30. https://doi .org/10.1177/0963662515593841.

Hall, E. T. (1976). Beyond culture. New York, NY, U.S.A.: Doubleday.

Harris, D. and Willoughby, H. (2009). 'Resuscitation on television: realistic or ridiculous? A quantitative observational analysis of the portrayal of cardiopulmonary resuscitation in television medical drama'. Resuscitation 80 (11), pp. 1275-1279. https://doi.org/10.1016/j.resuscitation.2009.07.008.

Hofstede, G. (2011). 'Dimensionalizing cultures: the Hofstede model in context'. Online Readings in Psychology and Culture 2 (1), pp. 1-26. https://doi.org/10.9707/2307-0919.1014.

Hofstede, G., Hofstede, G. J. and Minkov, M. (2010). Cultures and organizations: software of the mind. New York, NY, U.S.A.: McGraw-Hill. 
Huang, C.-J., Li, Y.-Y. and Lo, Y.-Y. (2020). 'Taiwan: from nationalizing science to democratizing science'. In: Communicating science: a global perspective. Ed. by T. Gascoigne, B. Schiele, J. Leach, M. Riedlinger, B. V. Lewenstein, L. Massarani and P. Broks. Canberra, ACT, Australia: ANU Press, pp. 849-862.

https://doi.org/10.22459/CS. 2020.

Jarrentrup, A., Mueller, T., Glowalla, U., Herder, M., Henrichs, N., Neubauer, A. and Schaefer, J. R. (2018). 'Teaching medicine with the help of "Dr. House"'. PLoS ONE 13 (3), e0193972. https://doi.org/10.1371/journal . pone. 0193972.

Kirby, D. A. (2003a). 'Science advisors, representation, and Hollywood films'. Molecular Interventions 3 (2), pp. 54-60. https: //doi .org/10.1124/mi .3.2.54.

- (2003b). 'Science consultants, fictional films, and scientific practice'. Social Studies of Science 33 (2), pp. 231-268. https://doi.org/10.1177/03063127030332015.

- (2008). 'Hollywood knowledge: communication between scientific and entertainment cultures'. In: Communicating Science in Social Contexts. New models, new practices. Ed. by D. Cheng, M. Claessens, T. Gascoigne, J. Metcalfe, B. Schiele and S. Shi. Dordrecht, Netherlands: Springer, pp. 165-180. https://doi.org/10.1007/978-1-4020-8598-7_10.

Landis, J. R. and Koch, G. G. (1977). 'The measurement of observer agreement for categorical data'. Biometrics 33 (1), pp. 159-174.

https://doi.org/10.2307/2529310.

Leonard, K. M., Van Scotter, J. R. and Pakdil, F. (2009). 'Culture and communication: cultural variations and media effectiveness'. Administration $\mathcal{E}$ Society 41 (7), pp. 850-877. https: //doi .org/10.1177/0095399709344054.

Massey, A. P., Hung, Y.-T. C., Montoya-Weiss, M. and Ramesh, V. (2001). 'When culture and style aren't about clothes: perceptions of task-technology "fit" in global virtual teams'. In: 2001 International ACM SIGGROUP Conference on Supporting Group Work (Boulder, CO, U.S.A. 30th September-3rd October 2001).

Masuda, T., Ellsworth, P. C., Mesquita, B., Leu, J., Tanida, S. and Van de Veerdonk, E. (2008). 'Placing the face in context: cultural differences in the perception of facial emotion'. Journal of Personality and Social Psychology 94 (3), pp. 365-381. https://doi.org/10.1037/0022-3514.94.3.365.

Moss-Wellington, W. (2020). 'Individual and collaborative labour in the space crisis movie: from Apollo 13 to The Martian'. Quarterly Review of Film and Video 37 (7), pp.634-657. https://doi.org/10.1080/10509208.2020.1731274.

National Communications Commission (2019). 107年度電視使用行為及滿意度調查 研究報告. [Annual report on TV users' behavior and satisfactions - 2018].

URL: https://www.ncc.gov.tw/Chinese/news_detail.aspx?site_content_sn $=4007 \&$ sn_f $=41451$.

Nisbett, R. E. and Masuda, T. (2003). 'Culture and point of view'. PNAS 100 (19), pp. 11163-11170. https://doi.org/10.1073/pnas.1934527100.

Owen, P. R. (2012). 'Portrayals of schizophrenia by entertainment media: a content analysis of contemporary movies'. Psychiatric Services 63 (7), pp. 655-659. https://doi.org/10.1176/appi.ps.201100371.

Pansegrau, P. (2007). 'Stereotypes and images of scientists in fiction films'. In: Routledge studies in science, technology and society. Ed. by P. Weingart and B. Hüppauf. London, U.K.: Routledge, pp. 257-266.

Peters, H. P. and Dunwoody, S. (2016). 'Scientific uncertainty in media content: introduction to this special issue'. Public Understanding of Science 25 (8), pp. 893-908. https://doi .org/10.1177/0963662516670765. 
Szu, E., Osborne, J. and Patterson, A. D. (2017). 'Factual accuracy and the cultural context of science in popular media: perspectives of media makers, middle school students, and university students on an entertainment television program'. Public Understanding of Science 26 (5), pp. 596-611. https://doi.org/10.1177/0963662516655685.

Tsai, Y. (1994). 'The correlative functions of Taiwan's television series'. Mass Communication Research 49, pp. 107-122. https://doi.org/10.30386/MCR.199407_(49).0006.

Wang, M.-J. (2000). 'A study of interaction between audience and TV drama series: how children interpret the sex-role stereotypes on soap opera'. Master's thesis. Taipei, Taiwan: Shih Hsin University.

Authors

\section{How to cite}

(C) The Author(s). This article is licensed under the terms of the Creative Commons Attribution - NonCommercial - NoDerivativeWorks 4.0 License. ISSN 1824-2049. Published by SISSA Medialab. jcom.sissa.it
Yin-Yueh Lo is an assistant professor in the Department of Communications Management, Shih Hsin University, Taiwan. Her research interests are scientists' involvement in public communication, and, in particular, their use of new media for public communication. She has worked on international projects and in two countries - Germany and Taiwan - and is very interested in how scientists' communication attitudes and practices vary across cultures. Currently, she is involved in research about the public relations activities of universities and research institutes in Taiwan. E-mail: yylo@shu.edu.tw.

Chun-Ju Huang is a full professor at the General Education Center of National Chung Cheng University, Taiwan. His research interests are anchored in three themes: public understanding of science, science communication, and general education in the science domain. He has written multiple articles on the Taiwanese media coverage of science, on the development of science communication in Taiwan, and on science in popular culture. E-mail: cjhuang@ccu.edu.tw.

Lo, Y.-Y. and Huang, C.-J. (2021). 'Differences in knowledge, uncertainty, and social context in four medical TV series from Taiwan, Japan, South Korea and the United States'. JCOM 20 (01), A01. https:/ / doi.org/10.22323/2.20010201. 